\title{
SERAT ECENG GONDOK SEBAGAI BAHAN ALTERNATIF ADMIXTURE PADA LASTON TIPE XI SNI 03-1737-1989 DITINJAU TERHADAP NILAI- NILAI UJI MARSHALL
}

\author{
Errine Yulia Rizqi Intanti'; Zulkifli Lubis ${ }^{2}$ \\ ${ }^{1}$ Program Studi Teknik Sipil Fakultas Teknik Universitas Islam Lamongan, \\ ${ }^{2}$ Dosen DPK Fakultas Teknik Program Studi Teknik Sipil Universitas Islam Lamongan, \\ email : errineyulia@gmail.com; cheppy.lubis@gmail.com
}

\begin{abstract}
In Indonesia, the road construction has experienced a fairly good development. From a wide range of road constructions, flexible pavement is the most chosen one because its characteristics: easy, fast, and efficient. However, flexible pavement has many weaknesses, for example the premature damage on the road surface after some time passed by the traffic so that the road cannot reach the planned age. For that, it is done a research to add a hot asphalt mixture material that aims to improve the quality of the mixture results. The selected ingredient is natural water hyacinth. The method used is trial and error with reference of SNI 03-17371989. Variations used are 2\%, 4\%, 6\%, 8\% and 10\% of the asphalt weight, asphalt level used is $5.72 \%$. Of the 5 variations of mixture used on Type XI Asphalt Concrete Layer, it is obtained the result that the water hyacinth fiber level which has the best score and meet the specifications of SNI 03-1737-1989 is on the percentage of 6\% which obtained from calculation data using graphs and regression model where Marshall Stability is equal to 644,46 Kg, flow $3,39 \mathrm{~mm}$, VMA (voids in the mineral aggregate) is equal to 13,83\%, VFWA (voids filled with asphalt) is equal to 65,35\%, VIM (voids in the mix) is equal to $2,52 \%$, density of $2.31 \mathrm{gr} / \mathrm{cc}$, and Marshall Quotient of $164.03 \mathrm{Kg} / \mathrm{mm}$.
\end{abstract}

Keywords : flexible pavement, Type XI asphalt concrete layer, water hyacinth fiber, marshall test

\section{PENDAhUluan}

Teknologi transportasi, khususnya pada konstruksi jalan raya telah mengalami perkembangan yang pesat. Hal ini ditandai dengan semakin lancarnya arus transportasi darat. Kehandalan teknologi dan ilmu pengetahuan sangat diharapkan untuk menghadapi tantangan dalam peningkatan kuantitas dan kualitas jalan yang akan dibangun dan dalam masa pemeliharaan dan diharapkan mampu memberikan umur teknis yang relatif lebih panjang dan dapat mengurangi kerusakan dini pada permukaan jalan (Kusuma, D., 2014).

Di indonesia umumnya pembangunan atau peningkatan jalan banyak menggunakan aspal minyak sebagai bahan pengikat, dan masih dijumpai beberapa kelemahan berupa kerusakan dini pada permukaan jalan setelah beberapa waktu dilalui oleh lalu lintas sehingga jalan tersebut tidak mencapai umur rencana, maka dari itu dengan teknologi yang sudah ada akan dilakukan suatu penelitian dengan menambahkan serat selulosa yang di dapatkan dari eceng gondok sebagai bahan campuran pada Laston. Fungsi serat selulosa sebagai bahan campuran aspal ini dapat menyerap aspal, memperkuat kekuatan ashesi dan dapat menstabilkan serta memperkuat aspal (Supriyadi, N., 2013).

Mengingat di daerah Lamongan tanaman eceng gondok tidak dimanfaatkan dengan baik dan menjadi limbah yang terbuang, untuk itu dalam penelitian ini akan menggunakan eceng gondok sebagai bahan campuran aspal panas. Penelitian ini dilakukan untuk mengetahui cara mengolah eceng gondok agar dapat dipergunakan sebagai bahan tambah pada campuran aspal, untuk mengetahui secara umum fungsi serat eceng gondok dalam meningkatkan mutu aspal, serta untuk 
mengetahui secara umum pengaruh penambahan serat eceng gondok terhadap karakteristik campuran aspal panas pada Laston Tipe XI SNI 03-1737-1989.

\section{METODE PENELITIAN}

Penelitian yang telah dilakukan di Laboratorium Teknik Sipil Universitas Islam Lamongan ini menggunakan metode Trial and Error atau coba-coba untuk mendapatkan kadar terbaik pada campuran aspal panas pada Laston Tipe XI SNI 03-1737-1989.

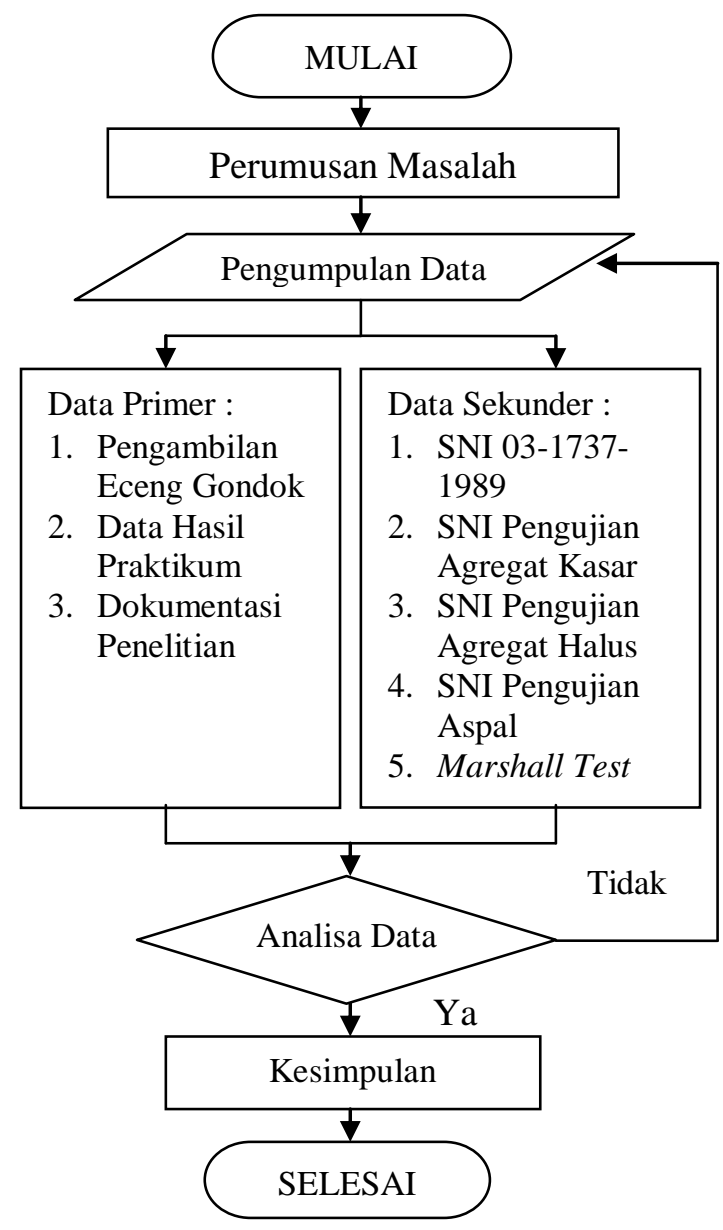

Gambar 1. Flowchart Alur Penelitian Sumber : Rancangan Penelitian, 2018

\section{HASIL DAN PEMBAHASAN Bahan Susun}

Bahan susun pembentuk campuran aspal panas yang terdiri dari agregat kasar, agregat halus dan aspal. Dari ketiga unsur penyusun campuran aspal panas diperlukan suatu pemeriksaan bahan susun dengan mengacu pada standart spesifikasi yang telah ditentukan. Pengujian bahan susun campuran aspal panas ini dilakukan di Laboratorium Universitas Islam Lamongan.

\section{Pemeriksaan Agregat Kasar dan Halus}

Dalam penelitian ini agregat kasar yang digunakan yaitu batu pecah asal Mojokerto dan agregat halus pasir dari kali brantas.

Pada pengujian agregat kasar dan halus dilakukan dua pemeriksaan, diantaranya yaitu pemeriksaan berat jenis dan penyerapan seperti pada tabel 1 dan 2 berikut :

Tabel 1 Hasil Pemeriksaan Agregat Kasar

\begin{tabular}{|c|c|c|}
\hline Jenis Pemeriksaan & Hasil & $\begin{array}{c}\text { Persyaratan } \\
\text { SNI 1969-2008 }\end{array}$ \\
\hline Berat Jenis Bulk & $2,51 \mathrm{gr} / \mathrm{cc}$ & $\geq 2,5 \mathrm{gr} / \mathrm{cc}$ \\
\hline Berat Jenis SSD & $2,55 \mathrm{gr} / \mathrm{cc}$ & $\geq 2,5 \mathrm{gr} / \mathrm{cc}$ \\
\hline Berat Jenis semu & $2,62 \mathrm{gr} / \mathrm{cc}$ & $\geq 2,5 \mathrm{gr} / \mathrm{cc}$ \\
\hline Penyerapan & $1,65 \%$ & $\leq 3 \%$ \\
\hline
\end{tabular}

Tabel 2 Hasil Pemeriksaan Agregat Halus

\begin{tabular}{lcc}
\hline Jenis Pemeriksaan & Hasil & $\begin{array}{c}\text { Persyaratan } \\
\text { SNI 1969-2008 }\end{array}$ \\
\hline Berat Jenis Bulk & $2,56 \mathrm{gr} / \mathrm{cc}$ & $\geq 2,5 \mathrm{gr} / \mathrm{cc}$ \\
Berat Jenis SSD & $2,61 \mathrm{gr} / \mathrm{cc}$ & $\geq 2,5 \mathrm{gr} / \mathrm{cc}$ \\
Berat Jenis semu & $2,68 \mathrm{gr} / \mathrm{cc}$ & $\geq 2,5 \mathrm{gr} / \mathrm{cc}$ \\
Penyerapan & $1,79 \%$ & $\leq 3 \%$ \\
\hline
\end{tabular}

Sumber : Hasil Penelitian dan Perhitungan, 2018

\section{Pemeriksaan Aspal}

Pada pemeriksaan, aspal yang digunakan yaitu aspal dengan pen 60/70 yang didapatkan dari PT. Cahaya Indah Madya Pratama. Terdapat beberapa jenis pemeriksaan yang dilakukan, diantaranya Uji Penetrasi, Uji Titik Nyala dan Bakar, Uji Titik Lembek, serta Uji Berat Jenis Aspal seperti pada tabel berikut :

Tabel 3 Hasil Pemeriksaan Aspal Pen 60/70

\begin{tabular}{|c|c|c|c|}
\hline $\begin{array}{c}\text { Jenis } \\
\text { Pemeriksaan }\end{array}$ & Hasil & Persyaratan & SNI \\
\hline $\begin{array}{l}\text { Penetrasi } 25^{\circ} \mathrm{C} \text {, } \\
100 \text { gr, } 5 \text { detik }\end{array}$ & $67 \mathrm{~mm}$ & $60-79 \mathrm{~mm}$ & $2456-2011$ \\
\hline Titik Nyala & $329^{\circ} \mathrm{C}$ & $\operatorname{Min} 200^{\circ} \mathrm{C}$ & 2433-2011 \\
\hline Titik Bakar & $334^{\circ} \mathrm{C}$ & $\operatorname{Min} 300^{\circ} \mathrm{C}$ & 2433-2011 \\
\hline Titik Lembek & $49,5^{\circ} \mathrm{C}$ & $48-58^{\circ} \mathrm{C}$ & 2434-2011 \\
\hline $\begin{array}{l}\text { Berat Jenis } \\
\text { Aspal }\end{array}$ & $\begin{array}{l}1,02 \\
\mathrm{gr} / \mathrm{cc}\end{array}$ & $\geq 1,00$ & $2441-2011$ \\
\hline
\end{tabular}

Sumber : Hasil Penelitian dan Perhitungan, 2018

\section{Perencanaan Campuran Kerja (Job Mix)}

Untuk memperoleh campuran bahan yang memenuhi spesifikasi diperlukan perencanaan campuran yang baik antar bahan penyusunnya. Perencanaan campuran ini 
dimaksudkan untuk menentukan proporsi penggunaan agregat kasar, agregat sedang, agregat halus dan pasir alami dalam campuran Laston Tipe XI SNI 03-1737-1989.

\section{Gradasi Agregat}

Setelah diperoleh komposisi campuran kemudian dilakukan penimbangan agregat sesuai dengan proporsi campuran Laston Tipe XI. Batasan gradasi agregat menurut spesifikasi Laston Tipe XI SNI 03-1737-1989 dapat dilihat pada grafik berikut :

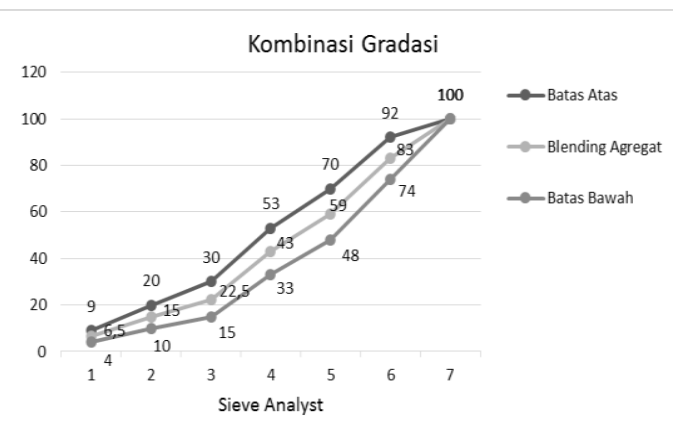

Gambar 2. Grafik Batasan Gradasi Agregat Sumber : Hasil Perhitungan, 2018

\section{Kadar Aspal Optimum}

Setelah menentukan batasan gradasi agregat yang akan digunakan, selanjutnya adalah menentukan kadar aspal optimum sebagai bahan campuran dan diperoleh dari perhitungan sebagai berikut :

$$
\begin{aligned}
\mathrm{KaO}= & 0,035 \times \mathrm{CA}+0,045 \times \mathrm{FA}+0,18 \\
& \mathrm{x} \text { Filler }+\mathrm{K} \\
\mathrm{KaO}= & 0,035 \times 41+0,045 \times 52,5+0,18 \\
& \mathrm{x} 6,5+0,75 \\
= & 5,72 \%
\end{aligned}
$$

Keterangan :

CA : Agregat kasar tertahan saringan No. 8

FA : Total agregat halus lolos saringan No. 8 dan tertahan No. 200

F : Filler agregat halus lolos saringan No. 200

K : Nilai Konstanta 0,75

\section{Hasil Pengujian Marshall Test}

Pengujian Marshall Test dilakukan bertahap sesuai dengan tujuan penelitian, yakni pertama dilakukan untuk mengetahui kadar aspal yang digunakan apakah sudah memenuhi syarat dan kedua untuk mengetahui pengaruh penambahan serat selulosa dalam campuran terhadap nilai-nilai Marshall Properties yaitu stabilitas Marshall (Marshall Stability), persentase Rongga Terisi Aspal (Void Filed With Asphalt / VFWA), Rongga Dalam Campuran (Void In The Mix / VIM), Rongga dalam agregat (Void In Mineral Aggregate), Kelelahan Plastis (Flow), dan Marshall Quotient (MQ).

\section{Stability Marshall}

Dari hasil uji Marshall didapatkan data kenaikan serta penurunan nilai Stability Marshall yang dipengaruhi oleh penambahan serat eceng gondok. Penurunan nilai stabilitas yang terjadi dipengaruhi oleh volume antar agregat yang terlalu tinggi serta penguncian antar partikelnya yang kurang merata sehingga menyebabkan nilai stabilitas tidak mencapai standart spesifikasi yang telah ditentukan. Selanjutnya dibuat permodelan grafik untuk melihat kenaikan serta penurunan nilai stabilitas sebagai berikut :

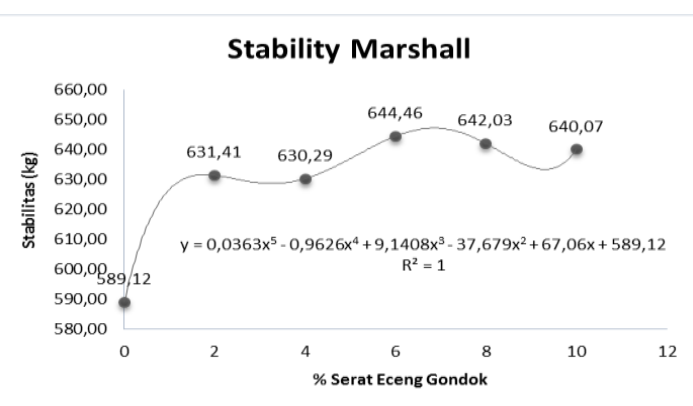

Gambar 3. Grafik Hubungan Stability Marshal dengan Kadar Serat Eceng Gondok Sumber : Hasil Perhitungan, 2018

Dari grafik hubungan stability marshall dengan kadar serat eceng gondok diatas dapat dilihat dari penambahan kadar serat 2\%-10\% nilai stabilitas sudah mencapai nilai standart spesifikasi yang telah ditentukan yaitu $550 \mathrm{~kg}$ menurut spesifikasi Laston SNI 03-17371989. Tetapi nilai tertinggi stability marshall terdapat pada penambahan kadar serat 6,8\%

\section{Voids Filled With Asphalt}

Penambahan serat eceng gondok juga mempengaruhi nilai VFWA (rongga terisi aspal) yang menyebabkan kenaikan serta penurunan yang disebabkan karena semakin banyak kadar serat selulosa eceng gondok yang digunakan, maka rongga yang ada dalam campuran akan menjadi besar dan campuran menjadi terpisah - pisah yang menyebabkan 
aspal tidak mengikat dengan baik. Selanjutnya dibuat permodelan grafik untuk melihat naik turunnya nilai VFWA sebagai berikut :

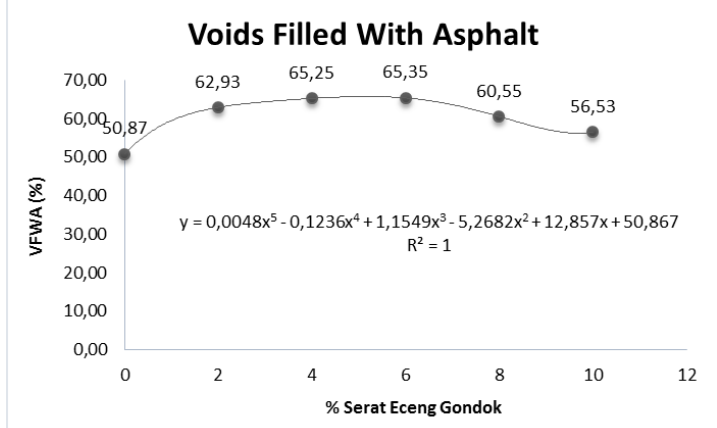

Gambar 4. Grafik Hubungan Voids Filled With Asphalt dengan Kadar Serat Eceng Gondok

Dari grafik diatas, nilai Voids Filled With Asphalt dengan mengalami kenaikan pada penambahan kadar serat $6 \%$, sebelum dan sesudah penambahan serat $6 \%$ mengalami kenaikan dan penurunan. Sehingga nilai Voids Filled With Asphalt tidak mencapai nilai standart. Sehingga nilai tertinggi terdapat pada penambahan kadar serat $6 \%$.

\section{Voids In The Mix}

Pada pengujian Marshall Test, nilai VIM atau rongga dalam campuran mengalami kenaikan serta penurunan yang dipengaruhi oleh penambahan kadar serat eceng gondok yang terjadi karena meningkatnya kadar serat dalam campuran, karena semakin banyak kadar serat dalam campuran akan membuat campuran menjadi terpisah-pisah karena aspal terserap oleh seret eceng gondok sehingga daya ikat aspal menjadi berkurang dan menyebabkan rongga-rongga dalam campuran meningkat. Untuk melihat kenaikan dan penurunan nilai VIM dibuat grafik sebagai berikut :

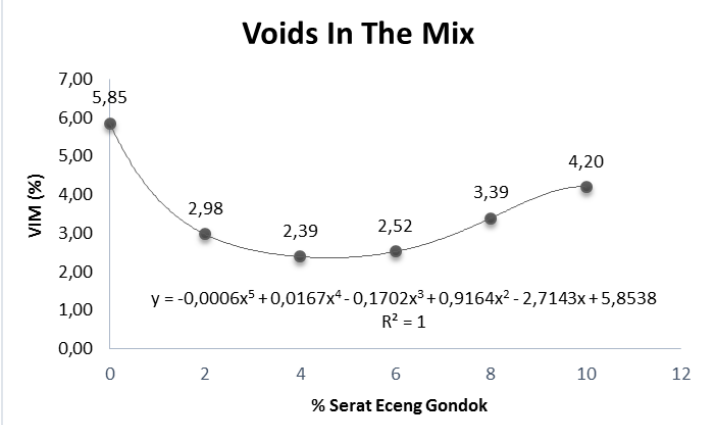

Gambar 5. Grafik Hubungan Voids In The Mix dengan Kadar Serat Eceng Gondok Sumber : Hasil Perhitungan, 2018
Dari grafik hubungan Voids In The Mix dengan kadar serat eceng gondok dapat dilihat bahwa penambahan serat eceng gondok membuat nilai VIM naik setelah terjadi penurunan pada penambahan kadar serat $2 \%$ $3 \%$ dan didapatkan nilai tertinggi pada penambahan kadar serat $10 \%$.

\section{Voids In Mineral Agregate}

VMA adalah rongga antar butiran agregat dalam campuran aspal yang sudah dipadatkan. Pada pengujian Marshall Test penambahan serat eceng gondok membuat nilai VMA mengalami kenaikan dan beberapa ada penurunan karena semakin banyak kadar serat selulosa eceng gondok yang digunakan, rongga-rongga dalam agregat akan menjadi besar sebab aspal tidak mengikat agregat dengan baik. Berikut merupakan grafik hubungan Voids In Mineral Agregate dengan kadar serat eceng gondok:

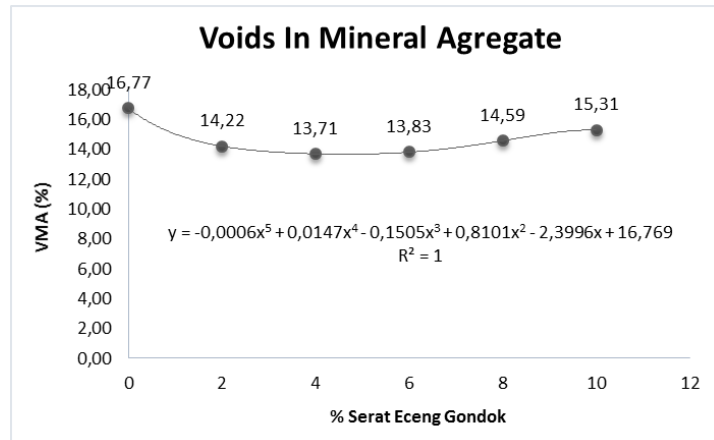

Gambar 6. Grafik Hubungan Voids In Mineral Agregate dengan Kadar Serat Eceng Gondok Sumber : Hasil Perhitungan, 2018

Dari grafik hubungan Voids In Mineral Agregate dengan kadar serat eceng gondok diatas didapatkan nilai tertinggi pada penambahan kadar serat $9,8 \%$.

\section{Density}

Density atau kepadatan merupakan berat isi dari campuran yang menunjukkan tingkat kerapatan suatu campuran yang telah dipadatkan. Pada pengujian Marshall Test, Penambahan serat eceng gondok berpengaruh terhadap density. Hal-hal yang mempengaruhi naik turunnya nilai density yaitu agregat yang digunakan sebagai bahan susun campuran tidak menyatu dengan sempurna dengan campuran aspal sehingga benda uji tidak terlalu padat dan pada proses penumbukan 
kurang maksimal. Selanjutnya dibuat permodelan grafik untuk melihat kenaikan dan penurunan nilai density sebagai berikut :

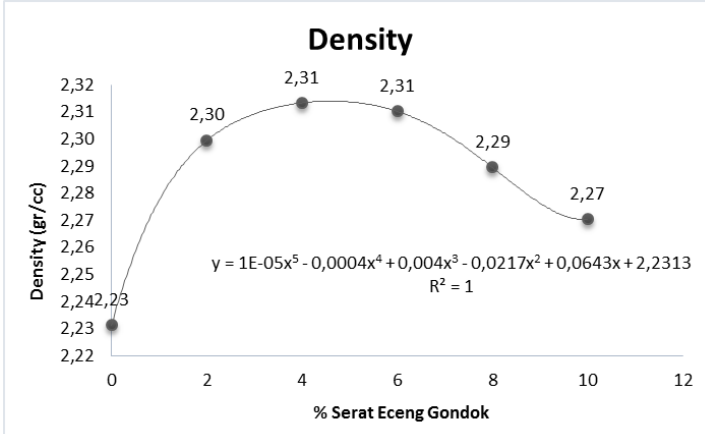

Gambar 7. Grafik Hubungan Density dengan Kadar Serat Eceng Gondok

Sumber : Hasil Perhitungan, 2018

Pada grafik diatas dapat dilihat hasil terbaik dari penambahan serat dan pada perhitungan didapatkan nilai Density terbesar pada penambahan serat $4 \%$.

\section{Flow}

Penambahan kadar serat eceng gondok mempengaruhi hasil dari kelelehan plastis (flow). Faktor yang mempengaruhi kenaikan serta penurunan pada flow yaitu semakin banyak penambahan serat eceng gondok, maka semakin berkurang kadar aspal sehingga mengakibatkan perekatan agregat dan aspal tidak sempurna dan menyebabkan kegetasan. Selanjutnya dibuat permodelan grafik untuk melihat kenaikan dan penurunan nilai flow sebagai berikut :

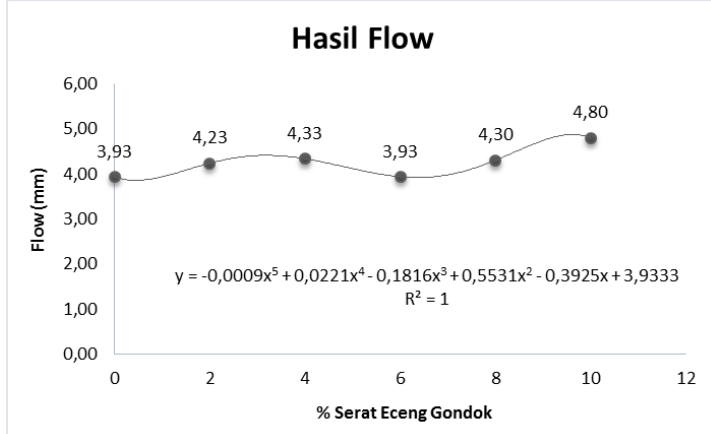

Gambar 8. Grafik Hubungan Flow dengan Kadar Serat Eceng Gondok

Sumber : Hasil Perhitungan, 2018

Dari grafik hubungan Flow dengan kadar serat eceng gondok diatas, didapat hasil terbaik pada penambahan kadar serat $6,4 \%$, sebelum dan sesudah penambahan kadar serat $6,4 \%$ nilai flow tidak memenuhi standart spesifikasi yang ditentukan.

\section{Marshall Quotient}

Marshall Quotient adalah hasil nilai bagi dari nilai stability marshall dengan flow. Pada pengujian marshall test, penambahan serat eceng gondok mempengaruhi penurunan serta kenaikan nilai MQ yang terjadi karena campuran aspal terlalu banyak yang menyebabkan benda uji terlalu lentur, serta campuran bahan tambah dan aspal tidak mengikat secara sempura. Kenaikan serta penurunan nilai marshall quotient dapat dilihat pada grafik berikut :

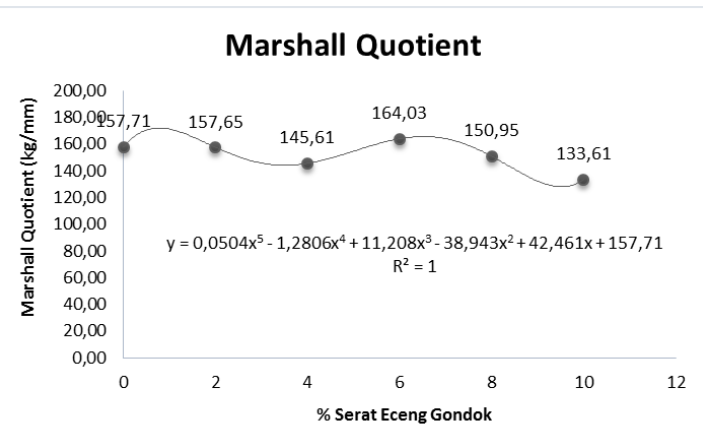

Gambar 9. Grafik Hubungan Marshall Quotient dengan Kadar Serat Eceng Gondok Sumber : Hasil Perhitungan, 2018

Dilihat dari grafik Hubungan Marshall Quotient dengan Kadar Serat Eceng Gondok diatas didapatkan nilai MQ terbesar atau mengalami kenaikan pada penambahan serat $6,4 \%$, sebelum dan sesudah penambahan serat $6,4 \%$ mengalami penurunan. Sehingga penambahan kadar serat terbaik untuk Marshall Quotient terdapat pada kadar 6,4\%.

Setelah didapatkan data dari pengujian Marshall Test yang bertujuan untuk mengetahui kadar aspal yang digunakan apakah sudah memenuhi syarat dan untuk mengetahui pengaruh penambahan serat selulosa dalam campuran terhadap nilai-nilai Marshall Properties yang meliputi pengujian stabilitas Marshall (Marshall Stability), persentase Rongga Terisi Aspal (Void Filed With Asphalt / VFWA), Rongga Dalam Campuran (Void In The Mix / VIM), Rongga dalam agregat (Void In Mineral Aggregate), Kelelahan Plastis (Flow), dan Marshall Quotient (MQ). Selanjutnya dibuat tabel 
rangkuman dari seluruh hasil pengujian

03-1737-1989 sebagai berikut :

Marshall Test serta standart spesifikasi SNI

Tabel 4 Hasil Pengujian Marshall Test dengan Penambahan Serat Eceng Gondok

\begin{tabular}{cccccccc}
\hline$\%$ Serat & $\begin{array}{c}\text { Stabilitas } \\
(\mathrm{kg})\end{array}$ & $\begin{array}{c}\text { VFWA } \\
(\%)\end{array}$ & $\begin{array}{c}\text { VMA } \\
(\%)\end{array}$ & $\begin{array}{c}\text { VIM } \\
(\%)\end{array}$ & $\begin{array}{c}\text { Density } \\
(\mathrm{gr} / \mathrm{cc})\end{array}$ & $\begin{array}{c}\text { Flow } \\
(\mathrm{mm})\end{array}$ & $\begin{array}{c}\text { MQ } \\
(\mathrm{kg} / \mathrm{mm})\end{array}$ \\
\hline 0 & 589,12 & 50,87 & 16,77 & 5,85 & 2,23 & 3,93 & 157,71 \\
2 & 589,12 & 62,93 & 14,22 & 2,98 & 2,30 & 4,23 & 157,65 \\
4 & 630,29 & 65,25 & 13,71 & 2,39 & 2,31 & 4,33 & 145,61 \\
6 & 644,46 & 65,35 & 13,83 & 2,52 & 2,31 & 3,93 & 164,03 \\
8 & 642,03 & 60,55 & 14,59 & 3,39 & 2,29 & 4,30 & 150,95 \\
10 & 640,07 & 56,53 & 15,31 & 4,20 & 2,27 & 4,80 & 133,61 \\
\hline Spesifikasi & Min 550 & Min 65 & Min 15 & $\mathbf{3 ~ - 5}$ & - & $\mathbf{2 ~ - 4}$ & $\mathbf{2 0 0}$ \\
\hline Pemadatan & $\mathbf{2} \mathbf{7 5}$ & & & Kadar Aspal & $\mathbf{5 , 7 2} \%$ & \\
\hline
\end{tabular}

Sumber : Hasil Perhitungan, 2018

Tabel 5 Penelusuran Model Regresi Pengaruh Penambahan Serat Eceng Gondok Terhadap Marshall Properties Campuran

\begin{tabular}{clcc}
\hline No & \multicolumn{1}{c}{ Marshall Properties } & \multicolumn{1}{c}{ Model Perumusan Regresi } & $\mathrm{R}^{2}$ \\
\hline 1 & Stability Marshall & $\mathrm{Y}=0,0363 \mathrm{x}^{5}-0,9626 \mathrm{x}^{4}+9,1408 \mathrm{x}^{3}-37,679 \mathrm{x}^{2}+67,06 \mathrm{x}+589,12$ & 1 \\
2 & Voids Filled With Asphalt & $\mathrm{Y}=0,0048 \mathrm{x}^{5}-0,1236 \mathrm{x}^{4}+1,1549 \mathrm{x}^{3}-5,2682 \mathrm{x}^{2}+12,857 \mathrm{x}+50,867$ & 1 \\
3 & Voids In The Mix & $\mathrm{Y}=-0,0006 \mathrm{x}^{5}+0,0167 \mathrm{x}^{4}-0,1702 \mathrm{x}^{3}+0,9164 \mathrm{x}^{2}-2,7143 \mathrm{x}+5,8538$ & 1 \\
4 & Voids In Mineral Aggregate & $\mathrm{Y}=-0,0006 \mathrm{x}^{5}+0,0147 \mathrm{x}^{4}-0,1505 \mathrm{x}^{3}+0,8101 \mathrm{x}^{2}-2,3996 \mathrm{x}+16,769$ & 1 \\
5 & Density & $\mathrm{Y}=1 \mathrm{E}-05 \mathrm{x}^{5}-0,0004 \mathrm{x}^{4}+0,0004 \mathrm{x}^{3}-0,0217 \mathrm{x}^{2}+0,0643 \mathrm{x}+2,2313$ & 1 \\
6 & Flow & $\mathrm{Y}=-0,0009 \mathrm{x}^{5}+0,0221 \mathrm{x}^{4}+0,1816 \mathrm{x}^{3}+0,5531 \mathrm{x}^{2}-0,3925 \mathrm{x}+3,9333$ & 1 \\
7 & Marshall Quotient & $\mathrm{Y}=1 \mathrm{E}-05 \mathrm{x}^{5}-0,0004 \mathrm{x}^{4}+0,004 \mathrm{x}^{3}-0,0217 \mathrm{x}^{2}+0,0643 \mathrm{x}+2,2313$ & 1 \\
\hline
\end{tabular}

Sumber : Hasil Perhitungan, 2018

Tabel 6 Nilai Kadar Serat Eceng Gondok Paling Ideal Dalam Campuran Lason Tipe XI SNI 031737-1989

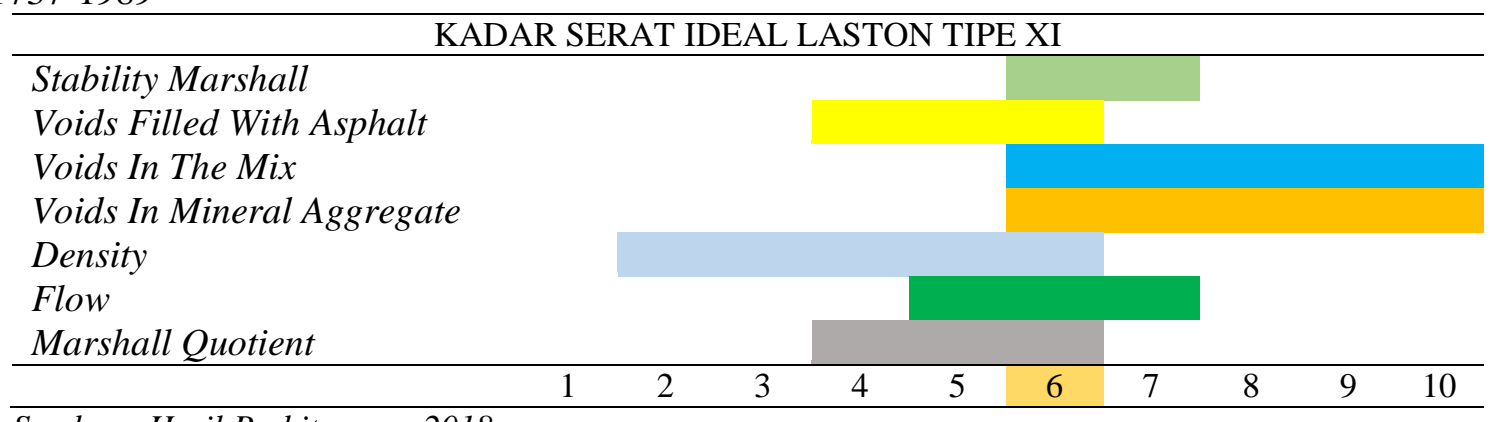

Sumber : Hasil Perhitungan, 2018

Pada Tabel 6 nilai kadar serat eceng gondok paling ideal dalam campuran Lason Tipe XI SNI 03-1737-1989 diatas dapat dilihat dari rangkuman hasil perhitungan menunjukkan bahwa serat eceng gondok terbaik atau yang paling ideal dalam campuran Laston tipe XI menunjukkan nilai terbaik pada penambahan kadar serat $6 \%$. Hasil ini dapat diketahui dari data grafik serta perhitungan model regresi yang telah dibuat, kadar 6\% telah memenuhi standart pada stabilitas, rongga terisi aspal (VFWA), rongga dalam campuran (VIM), kepadatan, kelelehan (Flow), serta Marshall Quotient nya.

\section{KESIMPULAN}

Dari penelitian yang telah dilakukan mengenai penambahan serat eceng gondok sebegai bahan alternatif admixture pada Laston tipe XI SNI 03-1737-1989 dan ditijau terhadap nilai-nilai uji marshall didapatkan kesimpulan dari hasil penelitian sebagai berikut :

1. Berdasarkan penelitian yang telah dilakukan, serat eceng gondok dapat 
digunakan sebagai bahan pengganti serat selulosa dan dapat digunakan sebagai bahan campuran aspal panas karena serat eceng gondok mampu menyerap aspal serta memperkuat aspal.

2. Dalam pembuatan serat econg gondok yang digunakan dalam penelitian ini dilakukan pengolahan dengan cara menghaluskan atau menggiling eceng gondok yang sudah di potong dan dibersihkan sampai mendapatkan karakteristik yang menyerupai serat selulosa yang sesungguhanya. Serat Eceng gondok sendiri dimaksdukan sebagai tambahan tambah yang dapat mengurangi banyaknya aspal yang digunakan dalam campuran.

3. Penambahan serat eceng gondok terhadap nilai-nilai Marshall Properties beberapa mengalami peningkatan.

4. Dalam penambahan serat eceng gondok sendiri mempengaruhi hasil dari Marshall Test yang mengalami kenaikan serta penurunan. Dari 5 variasi campuran yang digunakan pada campuran Laston tipe XI didapatkan kadar serat eceng gondok yang nilainya terbaik dan memenuhi spesifikasi SNI 03-1737-1989 adalah kadar serat 6\% yang di dapat dari data perhitungan menggunakan grafik serta perhitungan permodelan regresi, dimana Marshall Stability yang di dapatkan yaitu sebesar $644,46 \mathrm{Kg}$, Flow sebesar 3,39 mm , VMA (Rongga dalam agregat) sebesar 13,83\%, VFWA ( Rongga dalam udara ) sebesar $65,35 \%$, VIM (Rongga terisi aspal) sebesar $2,52 \%$, Density sebesar 2,31 gr/cc , dan Marshall Quotient sebesar 164,03 Kg/mm.

\section{SARAN}

Adapun beberapa saran dari penulis untuk penelitian selanjutnya agar dapat lebih baik dikemudian hari yaitu :

1. Dalam tahap pengolahan eceng gondok, sebaiknya digunakan alat khusus untuk menghaluskan atau menggiling serat agar didapatkannya karakteristik yang baik dan menyerupai serat selulosa yang sesungguhanya

2. Sebaiknya pada saat penelitian lebih banyak menggunakan variasi serat eceng gondok sebagai bahan perbandingan untuk mendapatkan kadar serat yang paling baik digunakan untuk bahan campuran aspal panas

3. Pada saat proses pemasakan atau pencampuran agregat dengan aspal kondisi suhu aspal saat dipanaskan harus lebih diperhatikan karena aspal yang tidak mencapai suhu optimal akan menjadi kental dan akan berpengaruh pada kondisi aspal saat ditumbuk

4. Dalam proses penimbangan bahan sebaiknya menggunakan alat timbang yang memiliki sistem digital agar dalam penimbangan bahan didapatkan hasil yang lebih akurat

5. Kondisi alat dan peralatan dalam pengujian sebaiknya menggunakan alat yang kondisinya baik agar didapatkan hasil yang akurat.

\section{REFERENSI}

SNI (1989). Tata Cara Pelaksanaan Lapis Aspal Beton (Laston) Untuk Jalan Raya. SNI 03-1737-1989.

SNI (2008). Cara Uji Berat Jenis Dan Penyerapan Agregat Halus. SNI 1970 : 2008 .

SNI (2011). Cara Uji Berat Jenis Aspal. SK SNI 2441-2011.

SNI (2011). Cara Uji Penetrasi Aspal. SK SNI 2456-2011.

SNI (2011). Pengujian Titik Lembek Aspal. SK SNI 2434-2011.

SNI (2011). Pengujian Titik Nyala dan Titik Bakar Aspal. SK SNI 2433-2011.

https://dwikusumadpu.wordpress.com/tag/asp halt-concrete-wearing-course/ Diakses tanggal 04 januari 2018

http://nanangsupriyadi.blogspot.com/2013/09/ perkerasan-lentur.html?m=1 Diakses tanggal 04 januari 2018 
Halaman ini sengaja dikosongkan 